\title{
An Assessment of Renal Function Parameters on the Ameliorative Properties of Ginkgo Biloba Extract in Cadmium-Induced Nephrotoxicity in Adult Wistar Rats Model
}

\author{
Ogunnaike Philip Olubunmi, Olatunji Sunday Yinka ${ }^{*}$, Owolabi Joshua Oladele, \\ Fabiyi Adetutu Olubusayo, Olanrewaju John Afees \\ Department of Anatomy, Benjamin Carson [Snr.] School of Medicine, Babcock University, Ilishan-Remo, Nigeria
}

\section{Email address:}

poogunnaike@yahoo.com (Ogunnaike P. O), adajosunday@yahoo.com (Olatunji S. Y.), olaowolabi001@yahoo.com (Owolabi J. O.), busayo-fabiyi@yahoo.com (Fabiyi A. O.), olanrewajuj@babcock.edu.ng (Olanrewaju J. A.)

${ }^{*}$ Corresponding author

\section{To cite this article:}

Ogunnaike Philip Olubunmi, Olatunji Sunday Yinka, Owolabi Joshua Oladele, Fabiyi Adetutu Olubusayo, Olanrewaju John Afees. An Assessment of Renal Function Parameters on the Ameliorative Properties of Ginkgo Biloba Extract in Cadmium-Induced Nephrotoxicity in Adult Wistar Rats Model. American Journal of Clinical and Experimental Medicine. Vol. 4, No. 4, 2016, pp. 112-117. doi: 10.11648/j.ajcem.20160404.15

Received: May 25, 2016; Accepted: June 2, 2016; Published: June 21, 2016

\begin{abstract}
Renal failure is a growing concern in the modern society and the increasing rate of exposure to toxic substances has contributed a lot to renal diseases. As a result of this, there is a great need for agents that can serve as nephroprotective. The present study assessed some parameters of renal function on the ameliorative properties of Ginkgo biloba extract (GBE) in cadmium (Cd) - induced nephrotoxicity in adult wistar rats model. The study was performed on twenty four (24) male Wistar rats divided into four groups: Group A (Control), Group B (Cd), Group C (Cd $+100 \mathrm{mg} / \mathrm{kg} \mathrm{BW}$ of GBE) and Group D (Cd + $300 \mathrm{mg} / \mathrm{kg}$ BW of GBE). The Cd and GBE were administered orally through oro-gastric cannula. The results showed changes in the renal function chemical parameters (creatinine, urea, and total protein) in the treated groups compared to the control group. Exposure to $\mathrm{Cd}$ lowered the activities of the kidney by increasing the plasma level of creatinine and urea, and decreasing the plasma level of total protein. The creatinine concentration decreased significantly $(p<0.05)$ in groups $\mathrm{C}$ and $\mathrm{D}$ while the urea concentration increased on GBE administration. A significant decrease was observed in the plasma total protein level in the Cd group when compared with the control and on administration of GBE there was an increase in the plasma total protein concentration in groups C and D. The results showed that Ginkgo biloba treatment ameliorated the effects of Cdinduced nephrotoxicity in all parameters except urea which is to be further investigated. These may be explained by the oxidative and anti-oxidative properties of the $\mathrm{Cd}$ and GBE respectively and their mechanisms of action.
\end{abstract}

Keywords: Ginkgo Biloba, Nephrotoxicity, Cadmium

\section{Introduction}

Renal failure is one of the commonest clinical symptoms that is caused by the inability of the kidney to remove metabolic end-products from the blood. It can occur as a short term (acute) or long term (chronic) disorder [1, 2]. Acute renal failure is usually unexpected in onset and often reversible if recognized early and treated appropriately, while chronic renal failure in contrast is the end result of irreparable damage to the kidneys; it develops slowly, usually over the course of a number of years [3]. One of the most common indicators of acute renal failure is accumulation of nitrogenous wastes (urea nitrogen, uric acid, and creatinine) in the blood. Also, in acute renal failure the glomerular filtration rate (GFR) is decreased. As a result, excretion of nitrogenous wastes is reduced and fluid and electrolyte balance cannot be maintained [4]. Persons with acute renal failure often are asymptomatic, and the condition is 
diagnosed by observation of elevations in blood urea nitrogen and creatinine levels [4]. Since the kidney is a vital organ in the body, having a primary role in maintaining homeostasis, it is important in toxicological processes. The mechanism underlying renal injury has been the focus of intense investigation for many years, and it has been suggested that inflammation and oxidative stress cause renal toxicity [5]

The activities of human contribute a lot in promoting environmental pollution by introducing unwanted toxic compounds which accumulate in water and food. Four main categories of pollutants that jeopardize the environments are radio nucleotides, petroleum hydrocarbons, pesticides and heavy metals, heavy metals being the most dangerous [6]. Hence industrial pollution of heavy metals is becoming a significant problem. Environmental pollution is a great cause of concern nowadays and the exposure of humans to heavy metals released into the environment by several sources produces deleterious and lethal effects [7]. Cadmium (Cd) is a non-essential heavy metal known to possess toxic effects on living things, in nature, it is not found in its pure form [8, 9]. Cadmium can be found almost everywhere; and its toxicity is of concern to industrial workers and all humans due to its use in some industrial products like batteries and also in agriculture $[10,11]$. Cadmium enters human and animal body orally by ingestion of contaminated food [12].

Herbal and natural products represent some of the most common forms of alternative medicines [13]. Various studies have shown antioxidant properties of several natural products against many toxic materials [14, 15]. Ginkgo biloba, also known as the maidenhair tree is the only living species in the division Ginkgophyta [16]. The tree is widely cultivated and is native to China. It has various uses in traditional medicine and as a source of food [16]. Extracts of Ginkgo biloba leaves contain phenolic acids, proanthocyanidins, flavonoid glycosides, biflavones, as well as alkylphenols and polyprenols [17]. Ginkgo biloba is a common plant used as a natural supplement. Ginkgo biloba extract is well known for its antioxidant properties, this may result from its ability to scavenge free radicals [17]. In developing countries, a large portion of the population depends heavily on traditional practitioners and medicinal plants for their health care needs. Ginkgo biloba leaves have been used as agents for improving cerebral circulation and are also said to have medicinal and therapeutic benefit such as anti-parasitic, anti-tumor and antiviral activities [18]. The role of Ginkgo biloba in the treatment of diseases associated with free radicals and oxidative stress has been suggested and tested [19] with various positive results. Here, the efficacy of Ginkgo biloba against heavy metal poisoning produced by cadmium $(\mathrm{Cd})$ would be tested for its ameliorative effects at different doses. Herbal and dietary substances that can considerably reduce the negative effects caused by metal toxicity are thus sought and presently, not enough evidence is available on the effects of Ginkgo-biloba on Cd-induced nephrotoxicity which is the rationale that formed the baseline for this study.

\section{Materials and Methods}

\subsection{Plant Extract}

Ginkgo biloba leaf extract made into capsules was gotten from Med Plus Limited Lagos Nigeria, a reputable drug store and taken to the Department of Anatomy, Babcock University, Ilishan-Remo Ogun State, Nigeria. The powdered extract was obtained from the capsule and weighed before it was dissolved in distilled water in the right proportions required for the experiment.

\subsection{Animal Care and Treatment}

A total number of 24 adult male Wistar rats (Rattus norvegicus) weighing between $120-170 \mathrm{~g}$ were obtained from the animal house of Babcock University, Ogun State. The rats were randomly divided into groups of four of six rats each (groups A, B, C and D). The animals were housed in clean, well ventilated plastic cages at room temperature, under natural light and dark cycles. The rats were left to acclimatize for 8 days and afterwards used for the experiment. Care and treatment of animals were performed accordingly. The following treatment protocol was used for this experiment:

Table 1. Grouping and treatment of experimental animals.

\begin{tabular}{ll}
\hline GROUPS & TREATMENT \\
\hline A & Control, rats received distilled water only \\
B & Negative control, Cadmium sulphate $(50 \mathrm{mg} / \mathrm{kg}$ body weight) only \\
C & Cadmium sulphate $(50 \mathrm{mg} / \mathrm{kg}$ body weight) for 7 days + Low dose, Ginkgo biloba $(100 \mathrm{mg} / \mathrm{kg}$ body weight) for 7 days \\
D & Cadmium sulphate $(50 \mathrm{mg} / \mathrm{kg}$ body weight) for 7 days + High dose, Ginkgo biloba (300mg/kg body weight) for 7 days. \\
\hline
\end{tabular}

Cadmium sulphate was obtained from Sigma ${ }^{\circledR}$ Chemicals, USA. Both Ginkgo biloba extract and Cadmium sulphate were dissolved in distilled water separately and administered daily through orogastric cannula throughout the period of administration, the dosage and time span chosen for this experiment were based on previous researches [20, 21], also a pilot study was carried out to arrive at the dosages used.

\subsection{Sacrifice and Biochemical Analysis}

The animals were sacrificed by cervical dislocation method, twenty four hours after the last administration. Blood samples were collected from the animals through cardiac puncture and were stored in EDTA bottles to obtain plasma. About $5 \mathrm{ml}$ of whole blood was collected into an 
EDTA bottle and centrifuged at 4000 revolutions for 15 minutes using Gulfex Medical and Scientific Centrifuge, England. The plasma was separated by decantation and analyzed for renal functions test with investigation of creatinine, urea and total protein levels. The analysis of creatinine, urea and total protein were determined following strictly the methods described by Ranjna [22].

\subsection{Statistical Analysis}

The data obtained were expresses as mean \pm Standard Error of Mean (S. E. M). The statistical significance was evaluated by one way analysis of variance (ANOVA) using GraphPad Prism (version 6). A value of $p<0.05$ was considered statistically significant.

\section{Results}

\subsection{Plasma Creatinine Level in Rats After Treatment}

As shown in figure 1, the plasma creatinine level of group B (Cd) $(0.4027 \pm 0.043)$ was significantly $(\mathrm{p}<0.05)$ higher when compared to the control group $(0.3132 \pm 0.018)$ and group $\mathrm{C}(\mathrm{Cd}+\mathrm{Ld} \mathrm{GBE})(0.3238 \pm 0.019)$, the difference between group $\mathrm{B}(\mathrm{Cd})(0.4027 \pm 0.043)$ and group $\mathrm{D}(\mathrm{Cd}+$ Hd GBE) $(0.3576 \pm 0.034)$ was not found to be statistically significant, however, there was an observable reduction in the plasma creatinine level of group $\mathrm{D}$ when compared to the Cd treated group (B). However, no significant difference was observed between groups $\mathrm{C}(\mathrm{Cd}+\mathrm{Ld} \mathrm{GBE})(0.3238 \pm 0.019)$ and $\mathrm{D}(\mathrm{Cd}+\mathrm{Hd} \mathrm{GBE})(0.3576 \pm 0.034)$ when compared with the control group $(\mathrm{A})(0.3132 \pm 0.018)$.

\section{CREATININE}

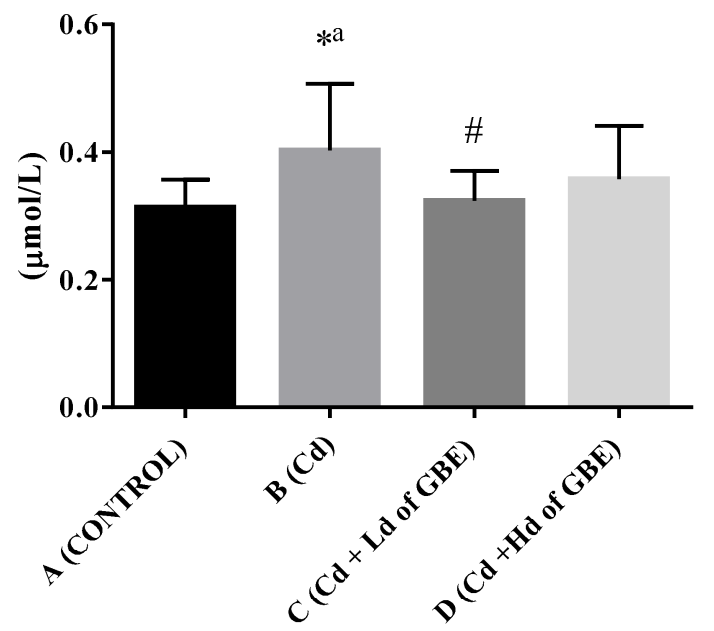

Figure 1. Plasma creatinine level ( $\mu \mathrm{mol} / L)$. Values are mean $\pm S E M$ of data obtained; * = significantly different from $A$ (control); \# = significantly different from $B(C d) ;{ }^{a}=$ significantly different from $C(C d+L d$ of $G B E)$, Cadmium (Cd), cadmium + low dose Ginkgo biloba (Cd + Ld of GBE), cadmium + high dose Ginkgo biloba $(\mathrm{Cd}+\mathrm{Hd} \mathrm{GBE})$.

\subsection{Plasma Urea Level in Control and Treated Group}

The plasma urea level in groups $\mathrm{C}(\mathrm{Cd}+\mathrm{Ld} \mathrm{GBE})(2.831$ $\pm 0.368)$ and group $\mathrm{D}(\mathrm{Cd}+\mathrm{Hd} \mathrm{GBE})(3.720 \pm 0.407)$ were significantly higher than the control group (A) $(1.369 \pm$ 0.044). Also, there was significant increase in plasma urea in group $\mathrm{C}(\mathrm{Cd}+\mathrm{Ld} \mathrm{GBE})(2.831 \pm 0.368)$ when compared to group $\mathrm{B}(\mathrm{Cd})(1.781 \pm 0.128)$ and this was also observed between group $\mathrm{D}(\mathrm{Cd}+\mathrm{Hd} \mathrm{GBE})(3.720 \pm 0.407)$ and group $\mathrm{B}(\mathrm{Cd})(1.781 \pm 0.128)$. That is, both $\mathrm{Cd}+\mathrm{GBE}$ groups had increased plasma urea concentration when compared to the $\mathrm{Cd}$ only treated group. The plasma urea level of group D $(\mathrm{Cd}$ + Hd GBE) $(3.720 \pm 0.407)$ was significantly $(\mathrm{p}<0.05)$ higher than group $\mathrm{C}(\mathrm{Cd}+\mathrm{Ld} \mathrm{GBE})(2.831 \pm 0.368)$. Although, no significant difference was found between group A (control) $(1.369 \pm 0.044)$, and group B (Cd) $(1.781 \pm$ 0.128). However, looking at the figure below, one could tell that there was an increase in the plasma urea concentration of group B in comparison with group A as shown in figure 2.

\section{UREA}

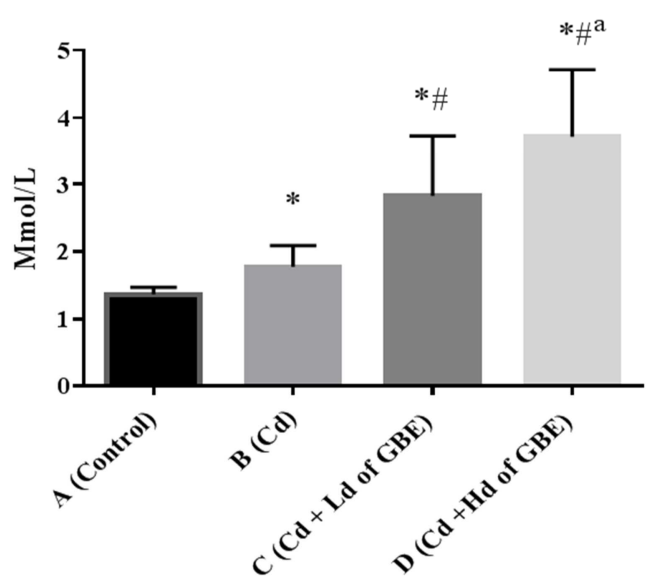

Figure 2. Plasma urea level (Mmol/L) Values are mean \pm SEM of data obtained; * = significantly different from $A$ (control); \# = significantly different from $B(C d) ;{ }^{a}=$ significantly different from $C(C d+L d$ of $G B E)$. Cadmium (Cd), cadmium + low dose Ginkgo biloba (Cd + Ld of GBE), cadmium + high dose Ginkgo biloba $(C d+H d G B E)$.

\subsection{Plasma Total Protein Level in Control and Treated Groups}

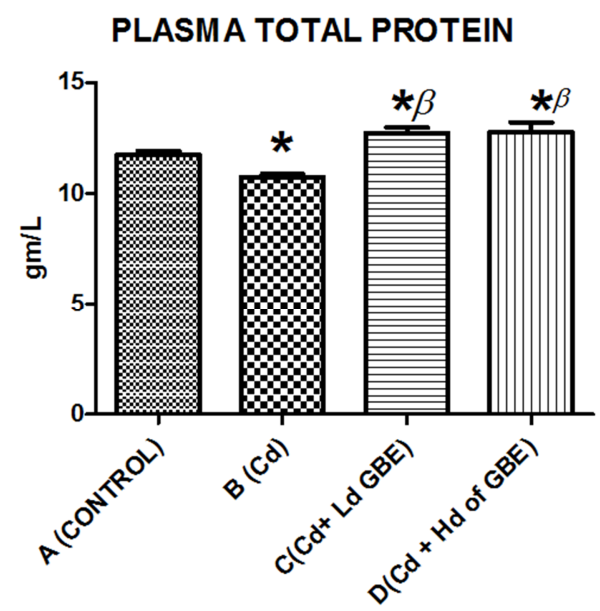

Figure 3. Plasma total protein level $(\mathrm{gm} / \mathrm{L})$ Values are mean \pm SEM of data obtained; * = significantly different from $A$ (control); $\beta=$ significantly different from $B(C d)$, Cadmium (Cd), cadmium + low dose Ginkgo biloba $(C d+L d$ of $G B E)$, cadmium + high dose Ginkgo biloba $(C d+H d G B E)$. 
As shown in figure 3, significant difference was observed between the control group (A) $(11.76 \pm 0.16)$ and group B (Cd) $(10.76 \pm 0.13)$. However, the plasma total protein levels in groups $\mathrm{C}(\mathrm{Cd}+\mathrm{Ld} \mathrm{GBE})(12.73 \pm 0.25)$ and $\mathrm{D}(\mathrm{Cd}+\mathrm{Hd}$ GBE) $(12.77 \pm 0.45)$ were significantly higher compared to group $\mathrm{B}(\mathrm{Cd})(11.11 \pm 0.27)$ and the control group (A) (11.76 $\pm 0.16)$. Also, group B (Cd) (10.76 \pm 0.13$)$ was significantly lower when compared with the control group (A) (11.76 \pm 0.16 ) and the rest of the treated groups i.e. groups $C$ and D.

\section{Discussion}

Many studies have shown detrimental effects (toxic, carcinogenic) of heavy metal $\mathrm{Cd}$ on human health due to the wide spread ability of this metal in the air (cigarette smoke, factory wastes), water (in pipelines) and plants [23, 24, 25]. The kidneys play a vital role in the elimination of toxic substances as a result of their ability in filtration, secretion and reabsorption and so the kidneys are more likely to be exposed to toxic materials compared to other organs [26, 27]. The toxicological evaluation of a substance in animal models is primordial for determining the potential risk for human life and is a necessary step to ensure the safety of a medication [28]. To this end, this study investigated the effects of Ginkgo biloba leaf extract on some markers of renal function of the kidney in rats with cadmium-induced kidney injury.

Plasma creatinine and urea concentrations in the blood are biomarkers of renal injury [29] and the elevation of these biomarkers is usually associated with impairment in renal function [30] because urea and creatinine are excreted through the kidneys, therefore in cellular damage, there is retention of urea and creatinine in the blood [31]. In this study, treatment of animals with Cd resulted in disturbance in kidney function, evidenced by increased levels of plasma urea and creatinine in the $\mathrm{Cd}$ group (B) when compared with the control and other experimental groups. This may be attributed to alterations in Glomerular Filtration Rate (GFR) leading to reduction in the amount of creatinine and urea that were filtered out of the blood. This is consistent with the work of Liu [32] in which he showed that Cd caused kidney damage. These changes could also be linked to oxidative imbalance in the kidney due to the presence of $\mathrm{Cd}$ causing elevation of these biomarkers in the blood. Findings from this study correlate with the report given by Gilrolami where urea level was elevated as a result of $\mathrm{Cd}$ induction [33].

Also, the significant increase in the level of creatinine in group B (Cd rat group) when compared with the control group (A), could also be attributed to oxidative damage to the kidney by the $\mathrm{Cd}$, in agreement with earlier reports [34] where $\mathrm{Cd}$ administration led to an elevated level of creatinine. Shatti reported rise in creatinine level to be an indication of renal tubular damage due to Cd-induced nephrotoxicity [35]. The significant increase in plasma concentration of creatinine is an evidence of reduced ability of the renal tubules to extract and remove creatinine from the plasma of the $\mathrm{Cd}$ group. The results seen in groups $\mathrm{C}(\mathrm{Cd}+\mathrm{Ld}$ GBE) and $\mathrm{D}(\mathrm{Cd}+\mathrm{Hd}$ $\mathrm{GBE}$ ), gives an indication that Ginkgo biloba has ameliorative effects on cadmium-induced kidney damage revealed by reduced plasma creatinine concentration. The creatinine level in group $\mathrm{C}(\mathrm{Cd}+\mathrm{Ld} \mathrm{GBE})$ was far more lower than that of group $\mathrm{D}(\mathrm{Cd}+\mathrm{Hd} \mathrm{GBE})$, indicating that treatment of nephrotoxicity induced by $\mathrm{Cd}$ with Ginkgo biloba is more effective at a low dose than it is at a high dose. There was no significant difference between the control rats and the rats of group $\mathrm{C}$ and $\mathrm{D}$ indicating that the GBE treatment brought back the functions of the kidney to an almost normal level, a fact supported by the study of Okuyan [36] where Ginkgo biloba restored the histoarchitecture of the kidney after being damaged by a toxic substance.

The significant increase in plasma concentration of urea is an evidence of the reduced ability of the renal tubules to extract and remove urea from the plasma of the $\mathrm{Cd}$ treated group, a fact supported by Girolami [33], it could also be as a result of diminished protein synthesis [37] in group B, this correlates with the effect that cadmium administration had on the level of total protein in group B. Treatment with Ginkgo biloba extract significantly increased the amount of urea retained in the blood of animals in groups $\mathrm{C}$ and $\mathrm{D}$, with the higher dose of Ginkgo biloba causing more urea retention, which can be likened to increased impairment in the filtration function of the kidney which is in contrast with earlier reports [20, 38] whose studies showed a decrease in urea concentration on Ginkgo biloba administration. It could be said that Ginkgo biloba reacts negatively with Urea excretion, thereby causing retention in the plasma urea concentration this can be further investigated.

The decrease in plasma total proteins in $\mathrm{Cd}$ treated rats may indicate disorders in protein synthesis, metabolism and necrosis as a result of individual actions or interactions of the complex constituents of the metal [39]. It has been similarly reported that $\mathrm{Cd}$ exposed rats showed reduced serum total protein with increased serum urea and creatinine due to functional damage to kidney [40]. On the other hand, GBE increased the amount of total protein in the plasma according to the doses administered in groups $\mathrm{C}$ and $\mathrm{D}$ even above the concentrations in the control group.

It may be deduced from this study that $\mathrm{Cd}$ induced nephrotoxicity in rats may be associated with free radical formation, supported by reports on activities of heavy metals analyzed [41, 42]. The alterations in glomerular function in $\mathrm{Cd}$ treated rats may also be secondary to reactive oxygen species (ROS), which induce mesangial cell contraction, altering the filtration surface area and modifying the ultra filtration coefficient factors that decrease the glomerular filtration rate [43].

The complex in the plasma is then filtered through the glomeruli in the kidney and taken up by the PCT [44]. On its way through the kidney, this complex causes injury especially in the cortical region, reaching the PCT and causing a gradual loss of the organ's function [45, 46]. Moreover these changes may be linked to the accumulation of free radicals as the consequence of increased lipid peroxidation by free $\mathrm{Cd}$ ions in the renal tissue of $\mathrm{Cd}$ treated rats [34] as the mechanism of Cadmium-induced kidney 
damage is considered to be related to increased oxidative status increasing free radical production [47].

It was reported that Ginkgo biloba extract possesses antioxidant properties. It is also known to be efficient in helping to treat or prevent diseases associated with free radicals [48]. Pharmacologically, there are two groups of substances that are significant compounds found in Ginkgo biloba extract; the flavonoids, which give Ginkgo biloba its antioxidant action, and the terpenes, which help to inhibit the formation of blood clots [49]. Anti-oxidants are agents that significantly inhibit the rate of oxidative activity [50]. Ginkgo biloba was able to reverse the effects of $\mathrm{Cd}$ by restoring the membrane of the Bowman's capsule and the tubules from oxidative degradation. This ameliorative property of Ginkgo biloba could be associated to the high concentration of flavonoids it contains because they possess the anti-oxidant property of the plant which help to fight off the free radicals produced by nephrotoxicants.

\section{Conclusion}

In conclusion, it was observed that treatment with Cadmium induced a significant elevation in the levels of plasma creatinine and urea and reduction in the plasma total protein. However, it was demonstrated that Ginkgo biloba at both high and low doses administered daily for 7 days conferred ameliorative potential by restoring these biomarkers with the low dose proving more effective in restoring renal functions, except in the case of urea where Ginkgo biloba caused a significant increase in the plasma urea concentration, this however remains controversial, and so further investigation is recommended. However, it can be suggested that Ginkgo biloba has ameliorative effects on cadmium-induced nephrotoxicity.

\section{References}

[1] Levy E. M., Viscose C. M., Horwitz R. I. (1996). The effect of acute renal failure on mortality: A cohort analysis. Journal of the American Medical Association 275, 1489-1494.

[2] Thadhani R., Pascual M., Bonventre J. V. (1996). Acute renal failure. New England Journal of Medicine 334, 1448-1460.

[3] Brady H. R., Brenner B. M., Clarkson M. R., et al. (2000). Acute renal failure. In Brenner B. M. (Ed.), Brenner and Rector's the kidney (6 ${ }^{\text {th }}$ ed., pp. 1201-1247). Philadelphia: W. B. Saunders.

[4] Guyton A., Hall J. E. (2000). Textbook of medical physiology (10 ${ }^{\text {th }}$ ed., pp. 369-371, 373-378). Philadelphia: W. B. Saunders.

[5] Schrier R. W., Wang W., Poole B. and Mitra A. (2004). Acute renal failure: definitions, diagnosis, pathogenesis, and therapy. The journal of Clinical Investigation, 114: p: 5-14.

[6] Gallo, Michael (2001). "History and Scope of Toxicology." In Casarett and Doull's Toxicology: The Basic Science of Poisons, $6^{\text {th }}$ edition, ed. Curtis D. Klaasen. New York: McGraw-Hill.
[7] Arisawa K, Uemura H, Hiyoshi M, Dakeshita, Kitayama A, Saito H, (2007) Cause-specific mortality and cancer incidence rates in relation to urinary beta 2-microglobulin: 23-year follow-up study in a cadmium-polluted area. Toxicol Lett. 28: 168-174.

[8] Long C, Juan Z, Wei G, Ying-Zi J (2003) Action of NO and TNF- $\alpha$ release of rats with cadmium loading in malfunction of multiple system organs. Acta Physiologica Sinica 55 (5): 535540 .

[9] Kaplan M, Atakan I. H, Aydigdu N, (2008) Influence of Nacetylcysteine on renal toxicity of cadmium in rats. Pediatr Nephrol 23: 233-241.

[10] Othman Z. A, Hashem A, Habila M. A (2011) Kinetic, equilibrium and thermodynamic studies of cadmium (II) absorption by modified agricultural wastes. Molecules 15: 10443-10456.

[11] Patra R. C, Rautray A. K, Swarup D (2011) Oxidative stress in lead and cadmium toxicity and its amelioration. Veterinary Medicine International. Vol 20: article ID: 457327.

[12] Baselt R. C. and Cravey R. H. Disposition of Toxic Drugs and Chemicals in Man, $4^{\text {th }}$ edition, Chemical Toxicology Institute, Foster City, CA, 1995, ISBN 0-9626523-1-8.

[13] Graham R. E, Ahn A. C, Davis R. B, O'Connor B. B, Eisenberg D. M, Phillips R. S. (2005). Use of complementary and alternative medical therapies among radical and ethnic minority adults: results from the 2002 National Health Interview Survey. J Natl Med Assoc 97: pp. 535-455.

[14] Shati A. A, Elsaid F. G. (2009). Effects of water extracts of thyme (Thymus vulgaris) and ginger (Zingiber offocinale Roscoe) on alcohol abuse. Food Chem Toxicol 47: 19451949.

[15] Shati A. A, Almari S. A. (2010) Role of saffron (Crocus sativus L.) and honey syrup on aluminium-induced hepatotoxicity. Saudi Med J 31: 1106-1113.

[16] [16] Mustoe, G. E. (2002). "Eocene Ginkgo leaf fossils from the Pacific Northwest". Canadian Journal of Botany 80 (10): 1078-1087.

[17] Van Beek T. A, Montoro P (2009). "Chemical analysis and quality control of Ginkgo biloba leaves, extracts, and phytopharmaceuticals". J Chromatography A 1216 (11): 20022032.

[18] Wadsworth T. L, Koop D. R (2001). Effects of Ginkgo biloba extract (EGb 761) and quercetin on lipopolysaccharideinduced release of nitric oxide. Chemico-Biological Interactions; 137 (1): 43-58.

[19] Bridi R, Crossetti FP, Steffen VM, Henriques AT (2001). The antioxidant activity of standardized extract of Ginkgo biloba (EGb 761) in rats. Phytotherapy Research. 15 (5): 449-451.

[20] Hamdy M. M, Dalia A. E, Abedlhamid M. M (2013) Protective effect of curcumin and Ginkgo biloba extract against Gentamicin-induced nephrotoxicity in rats. Assiut. Med. J. Vol. (37) 1, pg 1-12

[21] Naidu M. U, Schifow AA, Kumar KV, Ratnakar KS (2000). Ginkgo biloba extract ameliorates getamicin-induced nephrotoxicity in rats. 7 (3): 191-197. 
[22] Ranjna Chawla (1999), Practical Clinical Biochemistry; Methods and Interpretations, second edition. Jaypee Brothers Medical Publishers (P) Ltd. ISBN 81-7179-637-0.

[23] Nordberg M. and Nordberg G. F (2002). "Chapter 8," in Heavy Metals in the Environment, B. Sarkar, Ed., pp. 231-270, Marcel Dekker, New York, NY, USA.

[24] Chargui A, Zekri S, Rubera G. C. I (2011) Cadmium-induced autophagy in rat kidney: an early biomarker of sub-toxic exposure. Toxicol Sci 121 (1): pp. 31-42.

[25] Tripathi S, Srivastav A. K (2011) Cytoarchitectural alterations in kidney of Wistar rat after oral exposure to cadmium chloride. Tissue Cell 43 (2): 131-136.

[26] Proziaaleck W. C, Edwards J. R (2007) Cell adhesion molecules in chemically induced renal injury. Pharmacol Ther 114: 74-93.

[27] Boroushaki M. T, Mollazadeh H, Rajabian A, Dolati K, Hoseni A, Paseban M, Farzadina M (2014) Protective effect of pomegranate seed oil against mercuric chloride-induced nephrotoxicity in rat. Ren Fail 36 (10): 1581-1586.

[28] Asare G. A, Addo P, Bugyei K, Gyan B, Adjei S, Otu-Nyarko L. S, Wiredu E. K, Nyarko A (2011). Acute toxicity studies of aqueous leaf extract of Phyllanthus niruri. Interdiscip. Toxicol. 4: 206-210.

[29] Travlos G. S, Morris R. W, Elwell M. R, Duke A, Rosenblum S, Thompson M. B. (1996) Frequency and relationships of clinical chemistry and liver and kidney histopathology findings in 13-week toxicity studies in rats. Toxicology 107: 17-29.

[30] Kumar G, Banu S. G, Kannan V, Pandian R. M (2005) Antihepatotoxic effects of $\beta$ - carotene on paracetamol induced hepatic damage in rats. Ind J Exper Biol 43: 351-355.

[31] Ganong W. F. (2009) Review of Medical Physiology (23 ${ }^{\text {rd }}$ edition). Mc Graw-Hill: New York.

[32] Liu J, Habeebu SS, Liu Y, Klaassen CD (1998). Acute CdMT injection is not a good model to study chronic $\mathrm{Cd}$ nephropathy: comparison of chronic $\mathrm{CdC}_{12}$ and $\mathrm{CdMT}$ exposure with acute CdMT injection in rats. Toxicol Appl Pharmacol; 153 (1): 48-58.

[33] Girolami J. P, Cabos G, Manuel Y (1989). Renal kallikrin excretion as a distal nephrotoxicity marker during cadmium exposure in rat. J Toxicol 55: pp. 117-126.

[34] Renugadevi J, Prabu S. M (2009) Naringenin protects against cadmium-induced oxidative renal dysfunction in rats. Toxicol 256: $128-134$.

[35] Shatti A. A (2011) Effects of Origanum majorana L. On cadmium induced hepatotoxicity and nephrotoxicity in albino rats. Saudi Med J 32 (8): 15-20.

[36] Okuyan B, Izzettin F. V, Bingol-Ozakpinar O, Turan P, Ozdemir Z. N, Sancar M, Cirakli Z, Clark P. M, Ercan F. (2012). The effects of Ginkgo biloba on nephrotixicity induced by cisplatin-based chemotherapy protocols in rats. IUFS Journal of Biology 7 (2): 103-111.
[37] Olatunji S. Y, Adewole O. S, Ayannuga O. A, Taiye A. S, Adedayo A. D, Sesan O. O. (2015) Microanatomy and histomorphometry analysis of the effects of Moringa oleifera leaf extract on lead-induced kidney damage in adult wistar rats. Intl J. Biol. Chem. Sci. 9 (3): 1599-1614.

[38] Abd-Allh S. O (2014). Precautionary Effect of Ginkgo biloba Against Mercury-Induced Acute Nephro-Hepatotoxicity in male Rats. Journal of Babylon University/Pure and Applied Sciences. 9 Vol.(22). 2390-2405.

[39] Olivier B, Gregory J, Michel T, Marc C (2005) Effect of heavy metals on, and handling by, the kidney. Nephron Physiol. 99: 105-110.

[40] Morowati M. (2001) Biochemical and histopathological changes in serum creatinine and kidney induced by inhalation of Thimet (phorate) in male Swiss Albino mouse, Mus Musculus. Environ Res. 87: 31-36.

[41] Jadhav S. H, Sarkar S. N, Aggrawal M, Tripathi H. C (2007) Induction of oxidative stress in erythrocytes of male rats subchronically exposed to a mixture of eight metal found as groundwater contaminants in different parts of India. Arch Environ Contam Toxicol. 52: 145-151.

[42] Li G, Sang N, Guo D. (2006). Oxidative damage induced in hearts, kidneys and spleens of mice by landfill leachate. Chemosphere 65: 1058-1063.

[43] Zalpus R. K. (2000). Molecular interactions with mercury in the kidney. Pharmacol. Rev., 52: 113-143.

[44] Sudo J, Hayashi T, Kimura S, Kakuno K, Terui J, Takashima K, Soyama M. (1996). Mechanism of nephrotoxicity induced by repeated administration of Cadmium chloride in rats. Journal of Toxicology and Environmental Health 48 (4): 333 348 .

[45] Dorian C, Klaassen C. D. (1995). Protection by ZincMetallothionein (ZnMt) against Cadmium-Metallothionein (Cd-Mt) induced nephrotoxicity. Fundamental and Applied Toxicology 26 (1): pp. 99-106.

[46] Thijssen S, Maringwa J, Faes C, Lambrichts I, Kerkhove E. V. (2007). Chronic exposure of mice to environmentally relevant, low doses of cadmium leads to early renal damage, not predicted by blood or urine cadmium levels. Toxicology 229 (2): 145-156.

[47] Tang W and Shaikh Z. A. (2001). Renal cortical mitochondrial dysfunction upon cadmium metallathionein administration to sprague-dawley rats. J Toxicol Environ Health - Part A. 63 (3): 221-235.

[48] Yasuno F, Tanimukai Sasakib M, Ikejima C, Yamashita F, Kodama C, Mizukami K, Asada T (2012) Combination of antioxidant supplements improved cognitive function in the elderly. J Alzheimers Dis 32: 895-903.

[49] Singh B, Kaur P, Gopichand, Singh R. D, Ahuja PS. (2008). Biology and Chemistry of Ginkgo biloba. Fitoterapia. 79 (6): 401-418.

[50] Murray K. M, Granner D. K, Mayer P. A, and Rodwell V. W. (2000) Harpers Biochemistry $25^{\text {th }}$ edition 8: pp. 83-85, 130136. 